\title{
Microstructure Analysis and Rheological Behavior of Magnesium Alloys at Semi-solid Temperature Range
}

\author{
Marta Ślęzak, Piotr Bobrowski, and Łukasz Rogal
}

\author{
(Submitted March 7, 2018; in revised form July 9, 2018; published online August 13, 2018)
}

\begin{abstract}
Microstructure and rheological properties of AZ91 and Elektron 21 magnesium alloys in semi-solid state were studied. Differential scanning calorimetry revealed significant differences in melting range in analyzed materials. Isothermal annealing for 5,30 and $80 \mathrm{~min}$, in semi-solid range, corresponding to 50 and $70 \%$ of solid fraction, showed slower microstructure coarsening kinetics in Elektron 21 due to the presence of $\mathrm{Zr}$ and RE-enriched precipitations. Ostwald ripening and coalescence resulted in decrease in grains density with increasing annealing time and temperature. Hardness after annealing showed overall tendency to diminish with soaking time probably due to the growth of average grain size. Rheological analysis showed tendency to lower the value of dynamic viscosity coefficient as shear rate rise, which confirmed nonNewtonian flow behavior. The highest values of dynamic viscosity coefficient were obtained for alloy AZ91.
\end{abstract}

Keywords $\mathrm{Mg}$ alloys, microstructure, rheological properties, semi-solid state, thixoforming

\section{Introduction}

Magnesium alloys belong to a group of materials, which, due to a low specific gravity and good mechanical properties, may be a successful substitute for steel or aluminum (Ref 1). At present, the studies have been focused on developing new chemical compositions and their further optimizing as well as on new technologies of forming (Ref 1-3). The semi-solid metal processing (SSM) utilizes thixotropic flow in the solidusliquidus temperature range, which allows obtaining the components with complex shapes and high mechanical properties in a single operation ( $\operatorname{Ref} 2,3)$. It is possible due to unique microstructure consisting of the globular grains surrounded by homogeneously distributed eutectic (Ref 4). The rheological studies combined with the microstructural analysis constitute the basis for understanding the mechanisms of flow behavior of the slurry during a semi-solid metal processing (SSM) (Ref 1). The first rheological tests of solidifying alloys were conducted by Flemings and his co-workers. The investigations were performed while stirring the suspension at a specific, assumed temperature. The results of the experiments indicated the influence of the solid-phase content, the shear rate and the "alloy history," like time of stirring and staying on viscosity. The foregoing effects were related to the mechanism of merging and breaking the grain agglomerates, depending on "force" (Ref 2). The literature contains numerous studies on rheological analysis of aluminum and magnesium alloys (Ref 5-25), whose authors determined the values of dynamic viscosity coefficient (Ref 23, 49-53); however, these data did

Marta Ślezak, AGH University of Science and Technology, 30, Mickiewicza Av., 30-059 Kraków, Poland; Piotr Bobrowski and Lukasz Rogal, Institute of Metallurgy and Material Science, Polish Academy of Sciences, 25, Reymonta St., 30-059 Kraków, Poland. Contact e-mail: mslezak@agh.edu.pl. not concern the systems with the addition of rare earth elements. Many studies (Ref 10-12) indicated the positive effect of rare earth elements on microstructure and the mechanical properties of magnesium alloys after casting or plastic deformation. However, small number of results refers to RE containing magnesium alloys (e.g., Elektron E21) after annealing in the semi-solid state. It has been established that neodymium and gadolinium improve corrosion resistance and creep performance (Ref 40 ). It is connected with the fine-grain alloy structure as well as the presence of temperature resisting nano-precipitations. Understanding the changes occurring in the AZ91 and E21 microstructure after various conditions of treatment at the thixoforming temperature range can be helpful in the SSM optimization. Additionally, a comparison of the obtained results can be an easy way to demonstrate the influence of rare earth elements on microstructure of magnesium alloys.

The aim of this work was a complex characterization of rheological properties and microstructures of two kinds of magnesium alloys at semi-solid range. Thanks to the measurements of softening and the determination of shear rate dependency in function of temperature, it is possible to establish the behavior of metal suspension. The additional analysis of changes in the structure after cooling from 50 to $70 \%$ of solid fraction indicated a connection between the rheological properties and the microstructure.

\section{Experimental Procedure}

\subsection{Microstructure Analysis}

Two kinds of magnesium-based alloys with the chemical composition corresponding to the specification for AZ91 (EN-PN 1706:2002-8.7\%-Al, $0.7 \%-\mathrm{Zn}, \quad 0.4 \%-\mathrm{Si}$, 0.4-Mn, $\mathrm{Mg}$ balance, all in wt.\%) and Elektron 21 (AMS4429-0.3\%-Zn, $1.4 \%-\mathrm{Gd}, 3.0 \%-\mathrm{Nd}, 0.5 \%-\mathrm{Zr}$, $\mathrm{Mg}$-balance) were used in the present study. The alloys were supplied in the form of extruded rods (AZ91) by the Institute of Non-Ferrous Metals, Gliwice, and in the as-cast ingots by 
Magnesium Electron Ltd (Elektron 21, assigned in present work as E21). According to the DSC curve, the isothermal temperature was selected for the studied alloys: AZ91: 573 and $552{ }^{\circ} \mathrm{C}$, which corresponded to 50 and $70 \%$ of the solid fraction, respectively, and for $\mathrm{E} 21-641$ and $631{ }^{\circ} \mathrm{C}$, which corresponded to 50 and $70 \%$ of the solid fraction, respectively. The soaking time was selected as 5,30 and $80 \mathrm{~min}$ for the both alloys. The samples were introduced to a heated-up furnace and held for appropriate time, followed by water quenching. The chemical composition was determined using a JOBIN-YVON 10000 RF emission optical spectrometer.

The samples for the structural characterization were cut out from the longitudinal direction of the rod and the ingot. The $\mathrm{x}$ ray measurements of the phase composition were taken using a Philips PW 1710 diffractometer and Co Ka filtered radiation. The microstructure was examined using an FEI SEM XL30 scanning electron microscope (SEM) working in backscattered electron (BSE) or secondary electron (SE) modes. The quantitative metallographic analysis was performed using a Leica QUIN image analysis system and Image J software. The analyses were conducted at the optical images. In order to obtain reasonable statistical results during the particle average size analysis, about 1000 particles were evaluated in each specimen. Computer programs were used to calculate the size distribution of grains. The estimation of secondary phase amounts (liquid during semi-solid processing) was conducted based on contrast differences in the image analysis as well as applying manually selected image areas. The differential scanning calorimetry (DSC) was applied to measure the solidus-liquidus range and to determine the dependence of the liquid-phase amount in function of temperature using a Netzsch DSC404F1 apparatus. The samples, $3 \mathrm{~mm}$ in diameter and $2 \mathrm{~mm}$ thick, were heated in an alumina crucible at the rate of $15{ }^{\circ} \mathrm{C} / \mathrm{min}$ up to $700{ }^{\circ} \mathrm{C}$ in argon atmosphere. The determination of a fraction of the liquid phase as a function of temperature was calculated using data collected from the differential scanning calorimeter-heat flow curve. It was assumed that a fraction of a liquid phase is proportional to the absorbed/released energy during the transformation (melting/solidification). The estimation of the liquid-phase fraction changes was carried out by application of a partial peak area integration. Liquid fraction at a given temperature is determined by calculating the ratio of the area corresponding to the partial heat of melting over the total peak area. The Vickers hardness was measured using a Zwick/ZHU 250 tester under the load of $5 \mathrm{~kg}$.

\subsection{Rheological Analysis}

The rheological tests were carried out with a high-temperature rheometer (Ref 26-32), in the Searle-type cup and bob system (Ref 33-35). The high-temperature FRS1600 rheometer was designed within the cooperation of Anton Paar company and AGH University of Science and Technology, Faculty of Metals Engineering and Industrial Computer Science. Basically, it consists of the head of rheometer and the furnace which allows obtaining the temperature in the $400-1532{ }^{\circ} \mathrm{C}$ range. The measurement was taken in a fixed crucible, into which a sample of the tested material was placed and then a rotating spindle was immersed within the material being tested. The crucible was next placed inside a ceramic shroud, being a component of a heating furnace. The temperature inside the furnace was controlled by a change in feeder power. The heating rate, along with maintaining the temperature at a constant level, is set in the control panel of the Rheoplus software of the rheometer. Rotary movements of the spindle were controlled by a motorized measurement head - the spindle being suspended on a ceramic tube placed in an air bearing. The FRS1600 rheometer is a very precise instrument in which the measurement of the torque accuracy is $0.001 \mathrm{mNm}$. In this rheometer, the torque values are measured by the head and then the software calculates the values of shear stress, viscosity, etc. The parameters of the geometry of the measurement system are implemented in the Rheoplus software before starting the experiments. The details of the concentric cylinder measurement method (according to this apparatus) are described in Ref 35. Before every experiment, the motor adjustment and air check tests were made to verify the work of the head with air bearing (Ref 30 ). What is more, the tests at room and high temperatures with standard fluids were carried out before every measurement (Ref 30) and gave sufficient results in that case too. The protective gas was given during the whole test: from the beginning (heating) to the end (cooling the furnace with the sample). A special seal from the bottom side was used during the tests of very reactive magnesium alloys. The bobs with perforated surfaces of diameter $16 \mathrm{~mm}$, and the cups with smooth inner surfaces and the internal diameter of $30 \mathrm{~mm}$ were used for the tests. The tools were made of low-carbon steel to prevent reaction of the tool surface with the sample tested.

2.2.1 Viscosity Studies. Tools made of mild steel were used for the rheological measurement tests: a crucible (with a uniform geometry) (Fig. 1a).

In separate experiments, the AZ91 and E21 samples were heated to 650 and $700{ }^{\circ} \mathrm{C}$, respectively, and next cooled to temperatures of semi-solid range which corresponded to $f_{S}=50 \% \quad\left(\mathrm{AZ} 91-573{ }^{\circ} \mathrm{C}, \quad \mathrm{E} 21-641{ }^{\circ} \mathrm{C}\right) \quad$ and $f_{S}=70 \%$ (AZ91-552 $\left.{ }^{\circ} \mathrm{C}, \mathrm{E} 21-631^{\circ} \mathrm{C}\right)$. The cooling rate was $4{ }^{\circ} \mathrm{C} /$ min and shear rate was $10 \mathrm{~s}^{-1}$ during decreasing the temperature. The aim of the applied measurement was to analyze the rheological behavior of two various magnesium alloys at variable values of rheological parameters (shear rate, shear time) to enable the analysis of the influence of these factors on the "alloy history." When the temperature was reduced, a small shear rate was set $\left(10 \mathrm{~s}^{-1}\right)$ to stir the alloy slowly, without significant destruction of its internal structure. During the tests of magnesium alloys, which are very reactive, it was decided to carry out the measurements at the maximum shear rate of $150 \mathrm{~s}^{-1}$. The argument for using such a maximum shear rate was the fact that at such a high content of the solid phase in the alloy (50-70\%), the measuring instrument (a high-temperature rheometer) worked at the top range of the nominal torque of the measurement head.

2.2.2 Softening Test. Softening tests were conducted with the use of a high-temperature rheometer FRS1600. The drawing of the stamp is presented in Fig. 1(b).

Before starting the measurement, for each of the alloys tested, after setting the stamp to the crucible bottom, a sample was placed in the crucible and the stamp was lowered to touch the sample material. Cylindrical samples with the height of about $30 \mathrm{~mm}$ (AZ91: $29.2 \mathrm{~mm}, \mathrm{E} 21: 29.6 \mathrm{~mm}$ ) and the diameter of $20 \mathrm{~mm}$ were used for the tests. Next, a stamp force of $20 \mathrm{~N}$ was set and the furnace was turned on. During the measurement, changes of temperature and the sample heights were recorded. The measurement was taken in the range from room temperature to the temperature at which the material softened. 
(a)

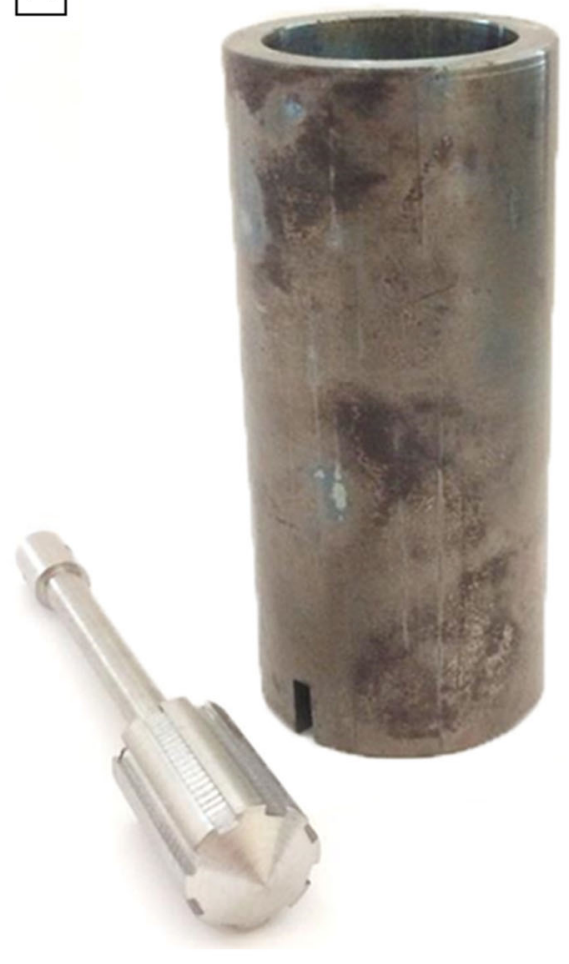

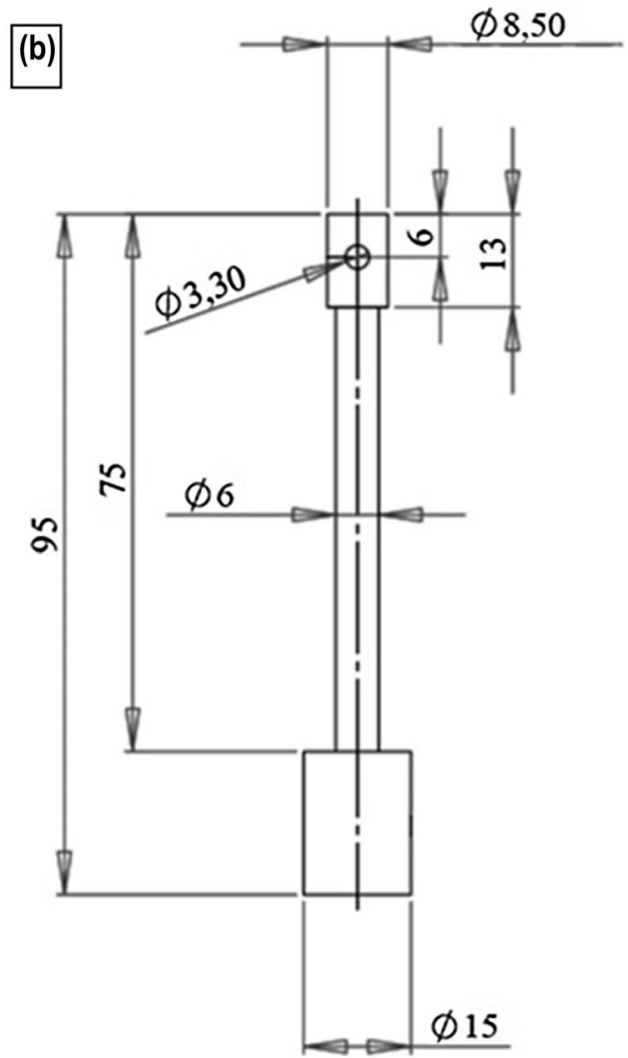

Fig. 1 Image of sets used for viscosity measurement (a) rotor with grooves and crucible made of steel (b) technical drawing of the stamp applied for the softening tests

\section{Results and Discussion}

\subsection{Analysis of Semi-Solid Range}

Two kinds of different magnesium alloys have been studied in the present work. AZ91 contains aluminum and zinc and is commonly used in foundry (Ref 36) due to good castability and satisfactory mechanical properties of the final products. E21 contains the additions of rare earth elements like $\mathrm{Gd}, \mathrm{Nd}$ as well as $\mathrm{Zr}$, which have significant impact on microstructure, leading to the grain refinement by the heterogeneous nucleation of $\operatorname{Mg}(\alpha) . \mathrm{ZnZr}_{2}$ precipitations on grain boundaries limit the microstructure coarsening (Ref 37). The positive effects of rare metals are visible in the improvement of the specific strength at both room and elevated temperatures, as well as the creep resistance (Ref 36-39). The chemistry of alloys is directly connected with melting temperatures, which were determined using DSC analysis (Fig. 2a and b).

The curves in Fig. 2(a) show heat flow signals for heating at the rate of $15^{\circ} \mathrm{C} / \mathrm{min}$ of the AZ91 and E21 magnesium alloys. Significant differences in the character of curves are visible. Melting can be divided into two parts. The first one starts in the temperature range between $420-440{ }^{\circ} \mathrm{C}$ and $540-565{ }^{\circ} \mathrm{C}$, visible as small endothermal effects, which are connected with melting of $\mathrm{Mg}_{17} \mathrm{Al}_{12}$ as well as $\mathrm{Mg}_{41} \mathrm{Nd}_{5}, \mathrm{Mg}_{3}(\mathrm{Gd}, \mathrm{Nd})$ intermetallics phases, respectively, for AZ91 and E21 (they were identified based on literature studies (Ref 39, 40) and the $\mathrm{x}$-ray analysis). Due to a low impact of melting/dissolution of intermetallic phases on total liquid fraction, they will be omitted during the estimation of their concentration at a given temperature. The magnesium solid solutions of AZ91 and E21 start melting at $458-620{ }^{\circ} \mathrm{C}$ and $578-674{ }^{\circ} \mathrm{C}$, respectively, which is visible in Fig. 2(a) as strong endothermic peaks.

On the basis of changes in the thermal effects during heating, the fraction of the liquid phase was determined in function of temperature (Fig. 2b). The graph allows the establishment of the corrected characteristic temperatures at the semi-solid range. In order to study the microstructure in this state, the experiments of its freezing by rapid cooling from the semi-solid range to water were conducted. Since the liquid phase during cooling transforms into eutectic, and due to high diffusivity of elements during cooling, some changes of microstructure take place. Nevertheless, this method is accepted in scientific field and often used (Ref 3 ).

\subsection{Microstructure Evolution in Solidus-Liquidus Range}

The microstructure analyses were conducted on the AZ91 and E21 samples after annealing at semi-solid range and subsequent cooling to water. Experiments were conducted at $50 \%$ of solid fraction (points $\mathrm{A}$ and $\mathrm{A}^{\prime}$ in Fig. 2b) and $70 \%$ of solid fraction (points B and $\mathrm{B}^{\prime}$ in Fig. 2b) in accordance with the DSC analysis. Examples of structures after soaking for 5, 30 and $80 \mathrm{~min}$ at 552 and $631{ }^{\circ} \mathrm{C}$ (which corresponded to $f_{S}=70 \%$ ) are presented in Fig. 3 .

Apart from different compositions, the alloys also had different starting microstructures before heating to SSM temperatures. Fine irregular grains of dimensions $45 \mu \mathrm{m}$ were visible in the extruded starting material of AZ91. They resulted from the dynamic recrystallization occurring during the hot 

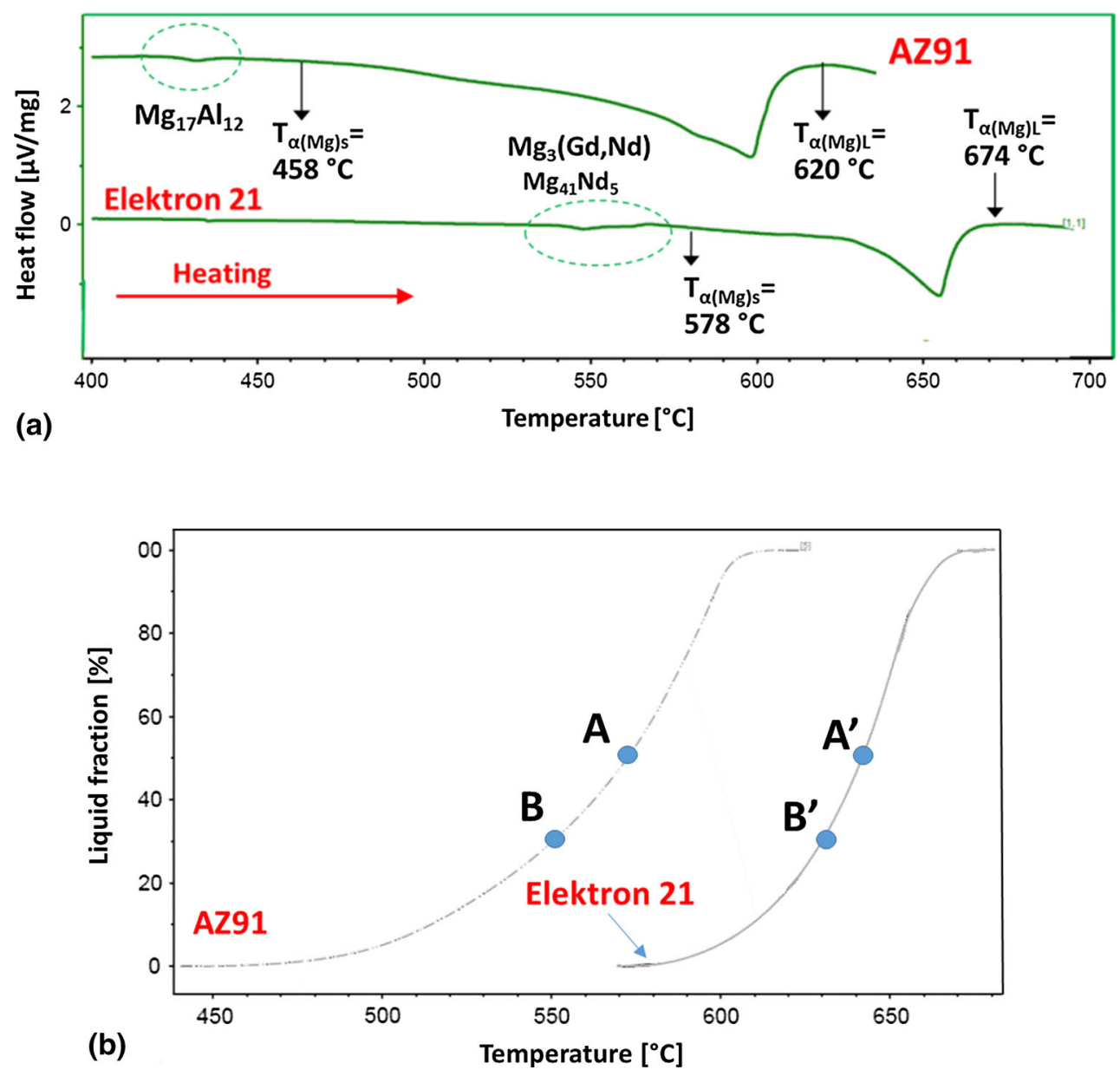

Fig. 2 DSC results of AZ91 and Elektron 21 examination: (a) heating flow curves, (b) liquid fraction curve in a function of temperature

deformation. Subsequent heating to the SSM temperature led to the penetration of liquid phase along the high-angle boundaries of the recrystallized grains and the spheroidization of the solid solution. This method of globular microstructure formation is called strain-induced melting activation process (SIMA) (Ref 3) and is a typical way of a globular microstructure preparation. Fine grains present in E21 (average size $52 \mu \mathrm{m}$ ) are connected with the heterogeneous nucleation of $\operatorname{Mg}(\alpha)$ during casting. In both cases, the microstructure coarsened with the increasing time of annealing (Fig. 3a-h). The amount of liquid phase was determined as $25 \pm 1.7$ and $24 \pm 1.7 \%$ on the basis of the content of the eutectic and secondary grain phases from the total area of AZ91 and E21, respectively. The differences in comparison with DSC can result from a strong non-equilibrium nature of the quenching process (higher cooling rate).

To illustrate better the evolution of the microstructure after isothermal holding, the grain sizes were analyzed using the theory of Ostwald ripening (Ref 4), which describes the time dependency of growing grain size with the classical Lifshitz, Slyozov and Wagner (LSW) relationship equation: $d^{3}-d_{0}^{3}=K t$, where $d_{0}$ is the initial grain size, $d$ the size at time $t, K$ the coarsening rate constant, and $\mathrm{n}$ the coarsening exponent. Figure 4( $a$ and $b)$ shows the changes of the average globule diameter as a function of isothermal soaking time for two various temperatures of the semi-solid state.

For $70 \%$ of the solid fraction, slower coarsening kinetics was observed in the E21 alloy, in which the value of the coarsening rate constant $(K)$ was $169 \mu \mathrm{m}^{3} \mathrm{~s}^{-1}$, while for AZ91 it reached $301 \mu \mathrm{m}^{3} \mathrm{~s}^{-1}$ (Fig. 4a). In the case of $50 \%$ of solid fraction, the curves of the AZ91 and E21 alloys have similar tendency; however, the rate of coarsening increased to 2018 and $214 \mu \mathrm{m}^{3} \mathrm{~s}^{-1}$, respectively. The density of grains is a factor directly related to the coarsening rate $(\operatorname{Ref} 3,4)$. Figure 5 shows the dependency of number of grains at a constant surface area on different temperatures and times of annealing.

It can be seen that the amount of grains decreases with increasing time of isothermal annealing and temperatures of semi-solid range.

The coarsening rate and grain density appear to be related to the initial microstructure, the alloy composition and liquid fraction content. It is well known that the presence of $\mathrm{Zr}$ enriched precipitations in the E21 alloy led to constraints in grain coarsening in the solid state as well as in the semi-solid temperature range (Ref 39) due to their high temperature stability (Ref 41). Another significant factor is the amount of solid fraction, which has a large impact on coarsening kinetics (Ref 4). Generally, the rate of semi-solid grain coarsening increases with the increasing fraction of solid $\left(f_{S}\right)$ (Ref 42). Such a phenomenon could be explained with the theory of liquid film migration, appropriate for the solid fraction of 0.7 (the exact value is dependent on the alloy and dihedral angle between the grains which are in contact with the liquid) (Ref $43,44)$. The system has a tendency to minimize energy, which happens in the alloy with a high liquid fraction by the 

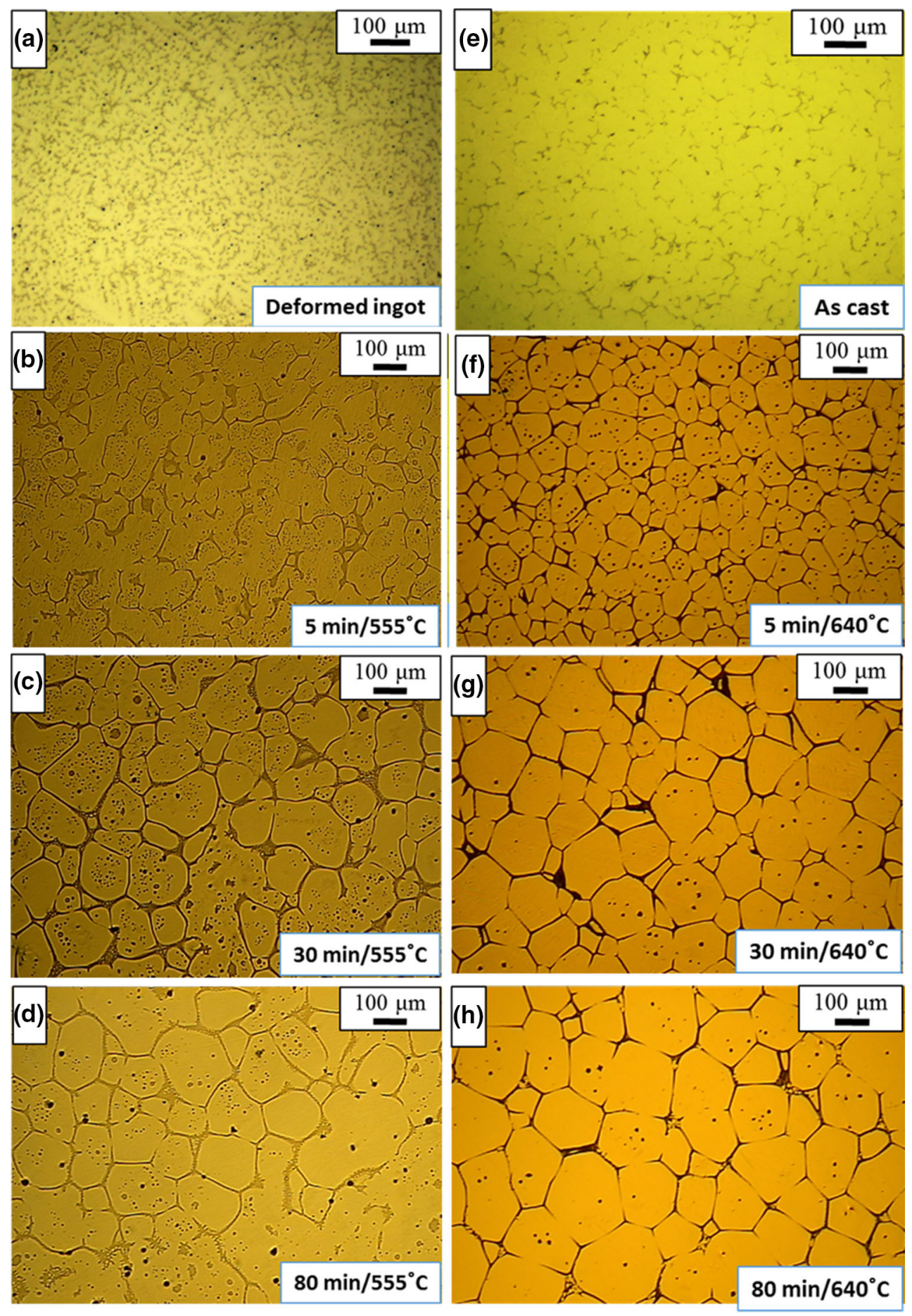

Fig. 3 Microstructures of AZ91 and E21 alloys isothermally held at 70\% of solid fraction for different periods of time. AZ91 (a) sample feedstock, held for (b) $5 \mathrm{~min}$, (c) $30 \mathrm{~min}$, (d) $80 \mathrm{~min}$, E21 (e) sample feedstock, held for (f) $5 \mathrm{~min}$, (g) $30 \mathrm{~min}$ (h) $80 \mathrm{~min}$

elimination of the interfaces of high curvature grain boundaries (Ref 45, 46). The Ostwald ripening and coalescence result in rapid coarsening and a significant decrease in grain density (Ref 4). The large grains become larger, and the small ones become smaller.

The detailed SEM and $\mathrm{x}$-ray analyses were performed in order to illustrate the changes of the microstructure after a longterm annealing. The SEM microstructures with the EDS point analysis for the AZ91 and E21 starting materials and the samples annealed for $80 \mathrm{~min}$ at $f_{S}=70 \%$ are shown in Fig. 6 .
Magnesium solid solution grains in the extruded AZ91 alloy are visible in the EDS analysis (point 1 in Fig. 6(a), Table 1), while the secondary phases are located between the grains (point 2, Fig. 6(b), Table 1). To show the effect of annealing on AZ91 microstructure, the SEM-BSE (Fig. 6b) with EDS analyses (points 1, 2, 3 in Fig. 6(b), Table 1) after treatment at $552{ }^{\circ} \mathrm{C}$ for $80 \mathrm{~min}$ were conducted. It can be seen that the concentrations of alloying elements ( $\mathrm{Al}$ and $\mathrm{Zn}$ ) in the grains are significantly higher in the annealed sample. It is directly 

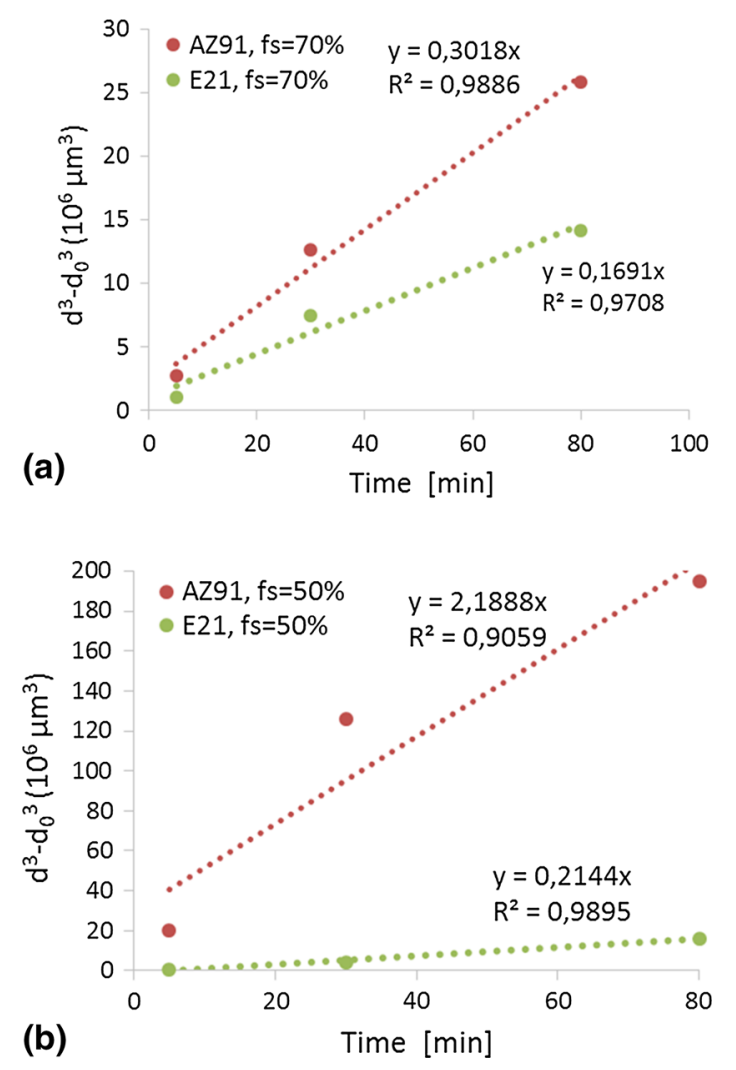

Fig. 4 Expression $d^{3}-d_{0}^{3}$ as a function of isothermal annealing of AZ91 and E21 magnesium alloys. The dotted lines represent the curves fitted to the classic LSW equation at $n=3$. The unit for $K$ in each case is $\mu \mathrm{m}^{3} \mathrm{~s}^{-1} . R^{2}$ is the regression coefficient, and $y$ is the equations of curves; (a) analysis for $70 \%$ of solid fraction, (b) analysis for $50 \%$ of solid fraction

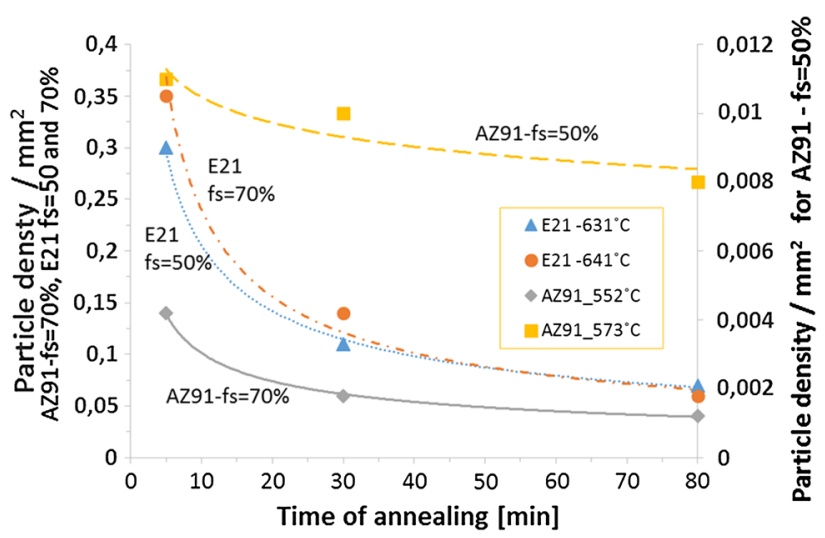

Fig. 5 The grains density in AZ91 and E21 after isothermal holding for 5, 30 and $80 \mathrm{~min}$ at 50 and $70 \%$ of solid fraction

connected with the decreased amount of the interglobular phase, whose components dissolved in the magnesium solid solution with increasing time of isothermal holding (due to increased size of $\operatorname{Mg}(\alpha)$ ). Additionally, large coarsening of eutectics, which is located inhomogeneously, is visible in the long-term annealed AZ91 sample. Similar behavior can be observed in the E21 as-cast state ingot (points 1, 2, 3, Fig. 6(c), Table 1) and after annealing (points 1, 2, 3 in Fig. 6(d), Table 1). However, the differences in composition are smaller than in the AZ91 samples. It should be noted that the eutectic precipitations in both cases reveal a higher concentration of alloying elements than in the grains.

The x-ray analyses allowed establishing the differences in lattice constants of $\operatorname{Mg}(\alpha)$, as well as in the phase composition depending on the state of materials (Fig. 7a and b).

It is clearly visible that the $\mathrm{a} / \mathrm{c}$ ratio of $\mathrm{Mg}$ cell slightly decreased in the samples annealed for a long time, which was connected with the diffusion of elements from the grains to the eutectic forming intermetallic phases (Table 2).

Additionally, in comparison with the starting material, intensity peak of intermetallic phases in annealed AZ91 increased, which is confirmed in the growth of its volume, while in the respective E21 samples the intensities were similar.

Studies of hardness changes with increasing time of annealing (Fig. 8) showed various behaviors of the analyzed magnesium alloys.

It should be noted that differences in hardness of the starting materials are the result of their various chemical compositions and different methods of the material preparation. AZ91 was subjected to hot extrusion, which led to the presence of strains and microstructure refining, while E21 was gravitationally cast to a metal die (achieving typical casting structure). The hardness of AZ91 continuously decreased with the lengthening soaking time, while that of the E21 alloy rose after 5 min of annealing, probably in connection with the super-saturation of $\operatorname{Mg}(\alpha)$. In the case of longer soaking time, the hardness decreased. It should be noted that alloys, independently of their chemical composition, revealed an overall tendency to achieve higher hardness in the samples with $70 \%$ of solid fraction than with $f_{s}=50 \%$ (after 80 min of annealing). This could be due to the average grain size factor, which was generally smaller in the samples annealed at lower temperatures. It was a result of Hall Patch dependency (Ref 47) which describes an improvement in mechanical properties of a fine microstructure due to grain boundary strengthening.

\subsection{Rheological Studies of AZ91 and E21 Magnesium Alloys}

In the source literature, authors took up the subject of dynamic viscosity of magnesium alloys (Ref 23, 48-52); however, their results did not concern the systems with the addition of rare earth elements. What is more, authors usually examined the rheological phenomenon of semi-solid slurries of alloys (Ref 23, 48-52). At the same time, the rheological behavior, i.e., thixotropy of the tested AZ91 alloy, was analyzed in a slightly different way, by studying the rest time and subjecting the system to the impact of forces, instead of gradual change of the shear rate (Ref 48, 49).

The viscosity measurements in the present study were as follows: Firstly, the sample was heated to their liquid state and then the temperature was homogenized in a whole volume of the sample (waiting for about $20 \mathrm{~min}$ after reaching the assumed temperature value). After homogenization, the measurements of totally liquid alloys at shear rate $10 \mathrm{~s}^{-1}$ were provided; next the temperature started decreasing to the temperature equal to $f_{s}=50 \%$ for each of the investigated alloys (constantly stirring at shear rate $10 \mathrm{~s}^{-1}$ ). After obtaining and stabilizing the temperature in the whole sample volume, the tests with different shear values were performed: 10, 100, 10$150,150-10 \mathrm{~s}^{-1}$. Then, the temperature was decreasing again - to obtain solid fraction in the sample equal to $70 \%$. The temperature was again stabilized, and investigations for different shear values were applied. 

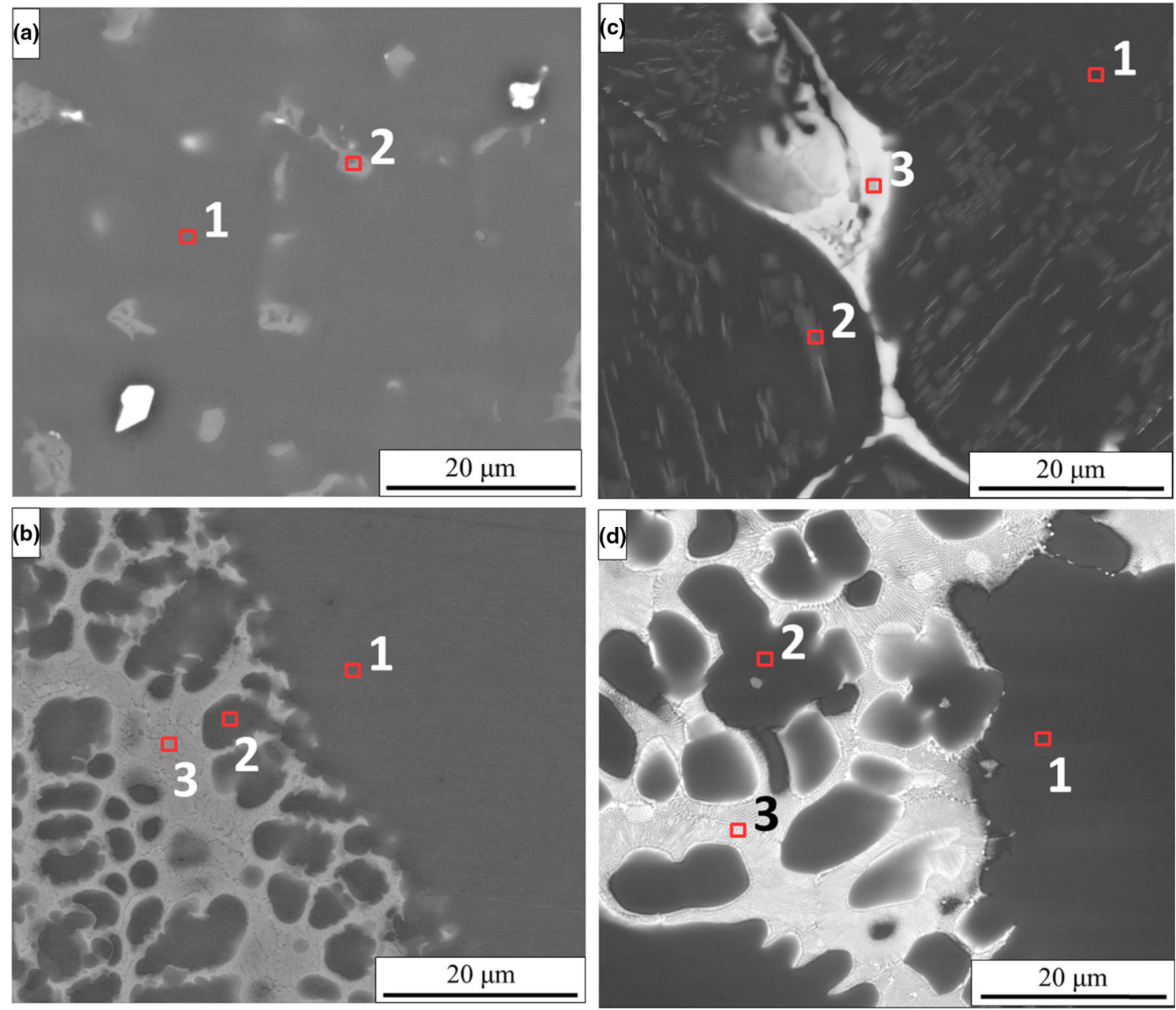

Fig. 6 SEM microstructures of AZ91 (a) extruded bar, (b) after annealing at $552{ }^{\circ} \mathrm{C}$ for 80 min, and E21 (c) as-cast state-ingot, (d) after annealing at $631{ }^{\circ} \mathrm{C}$ for $80 \mathrm{~min}$

Table 1 SEM-EDS analysis results of the areas shown in Fig. 7

\begin{tabular}{|c|c|c|c|c|c|c|c|}
\hline \multirow[b]{2}{*}{ Place of analysis } & \multirow[b]{2}{*}{ Point of analysis } & \multicolumn{6}{|c|}{ Content, wt.\% } \\
\hline & & Al & $\mathbf{Z n}$ & Gd & Nd & $\mathbf{Z r}$ & Mg \\
\hline \multirow[t]{2}{*}{ Figure 7a (AZ91—bar) } & 1 & 4.4 & 0.2 & $\ldots$ & $\ldots$ & $\ldots$ & Bal. \\
\hline & 2 & 25.6 & 4.4 & $\ldots$ & $\ldots$ & $\ldots$ & Bal. \\
\hline \multirow[t]{3}{*}{ Figure $7 \mathrm{~b}$ (AZ91 - annealed } & 1 & 5.2 & 0.4 & $\ldots$ & $\ldots$ & $\ldots$ & Bal. \\
\hline & 2 & 12.8 & 1.1 & $\ldots$ & $\ldots$ & $\ldots$ & Bal. \\
\hline & 3 & 30.2 & 4.2 & $\ldots$ & $\ldots$ & $\ldots$ & Bal. \\
\hline \multirow[t]{3}{*}{ Figure 7c (E21-ingot) } & 1 & $\ldots$ & 0.2 & 0.5 & 1.1 & 2.3 & Bal. \\
\hline & 2 & $\ldots$ & 0.4 & 1.5 & 3.6 & 0.4 & Bal. \\
\hline & 3 & $\ldots$ & 2.5 & 3.4 & 33.3 & 0.1 & Bal. \\
\hline \multirow[t]{3}{*}{ Figure $7 \mathrm{~d}(\mathrm{E} 21$ - annealed) } & 1 & $\ldots$ & 0.1 & 0.8 & 1.0 & 0.4 & Bal. \\
\hline & 2 & $\ldots$ & 0.0 & 1.9 & 3.3 & 0.2 & Bal. \\
\hline & 3 & $\ldots$ & 2.2 & 5.5 & 27.5 & 0.2 & Bal. \\
\hline
\end{tabular}

Figure 9 presents a graph of changes in the dynamic viscosity coefficient of alloy AZ91 versus temperature.

The temperature varied from that of liquidus to $573{ }^{\circ} \mathrm{C}$, at which the alloy (in accordance with the DSC analysis) contained $50 \%$ of the solid phase. The graph depicts "momentary" jumps of the dynamic viscosity coefficient (from the initial values of 0.18 to $1.8 \mathrm{~Pa} \mathrm{~s}$ ), which were likely to be caused by the emergence of crystals sheared by the slowly turning spindle (Ref 48). The average value of the dynamic viscosity coefficient of alloy AZ91 at $573{ }^{\circ} \mathrm{C}$ was about $0.6 \mathrm{~Pa} \mathrm{~s}$.

Figure 10 shows changes of dynamic viscosity coefficient of alloy AZ91 versus temperature.

The temperature changed from that, at which the alloy had $50 \%$ solid phase $\left(573{ }^{\circ} \mathrm{C}\right)$, to the temperature at which the alloy contained $70 \%$ solid phase (temp. $552{ }^{\circ} \mathrm{C}$ ). However, it is 

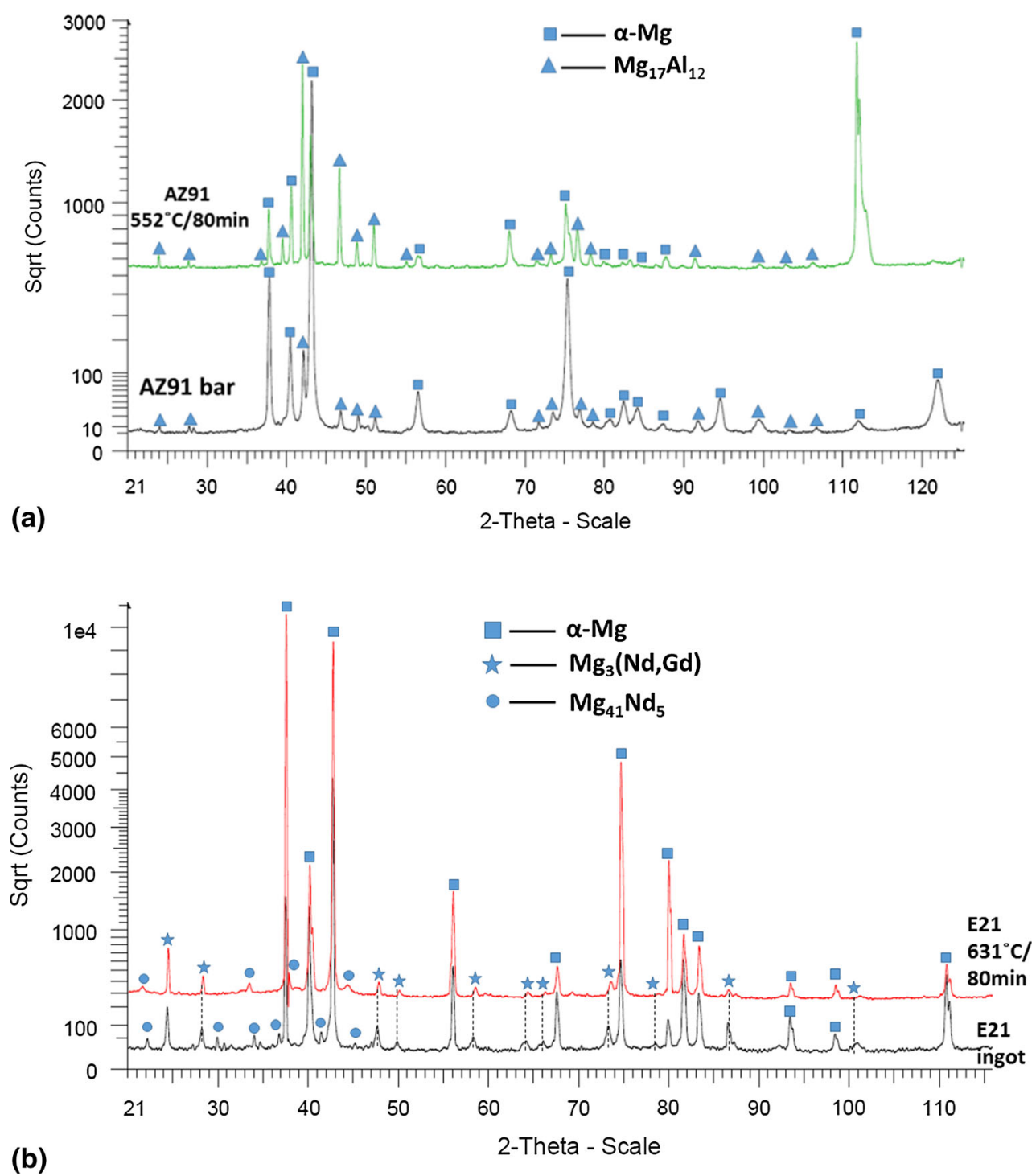

Fig. 7 X-ray diffraction patterns of (a) AZ91: bar—bottom, after annealing—upper, (b) E21: ingot bottom pattern, upper pattern—annealed

Table 2 Lattice constant parameters for AZ91 and E21 at various states

\begin{tabular}{|c|c|c|c|}
\hline \multirow{2}{*}{$\begin{array}{l}\text { Alloy } \\
\text { AZ91—bar }\end{array}$} & \multicolumn{2}{|c|}{ Lattice constants } & \multirow{2}{*}{$\begin{array}{c}\boldsymbol{c} / \boldsymbol{a} \\
1.622\end{array}$} \\
\hline & $a$ & 3.190 & \\
\hline & $c$ & 5.177 & \\
\hline \multirow{2}{*}{$\mathrm{AZ} 91-80 \mathrm{~min} / 552{ }^{\circ} \mathrm{C}$} & $a$ & 3.203 & 1.613 \\
\hline & $c$ & 5.169 & \\
\hline \multirow[t]{2}{*}{ E21-ingot } & $a$ & 3.220 & 1.621 \\
\hline & $c$ & 5.222 & \\
\hline \multirow[t]{2}{*}{$\mathrm{E} 21-80 \mathrm{~min} / 631^{\circ} \mathrm{C}$} & $a$ & 2.215 & 1.620 \\
\hline & $c$ & 5.211 & \\
\hline
\end{tabular}

needed to emphasize that the measurement for a single alloy consisted of a group of tests at different temperatures and shear rates. Thus, the graphs of temperature changes for the $70 \%$ solid fraction were drawn after a series of the tests for $50 \%$ of solid fraction and the difference of "initial" value of dynamic viscosity coefficient (for the same temperature) was the effect of the "alloy history." Significant growth of the dynamic viscosity (from the initial values of 12 to about $50 \mathrm{~Pa} \mathrm{~s}$ ) could be observed. The increase in apparent viscosity values of the AZ91 alloy with increasing solid fraction was also reported by Chen et al. (Ref 50). However, one should bear in mind that in such conditions, for such a high solid-phase share in the material and, at the same time, very slow stirring, the alloy structure can "reconstruct" and "seize" the measurement spindle. The rheological behavior under different shear time was analyzed by Chen and Chen (Ref 49) too, and they also 


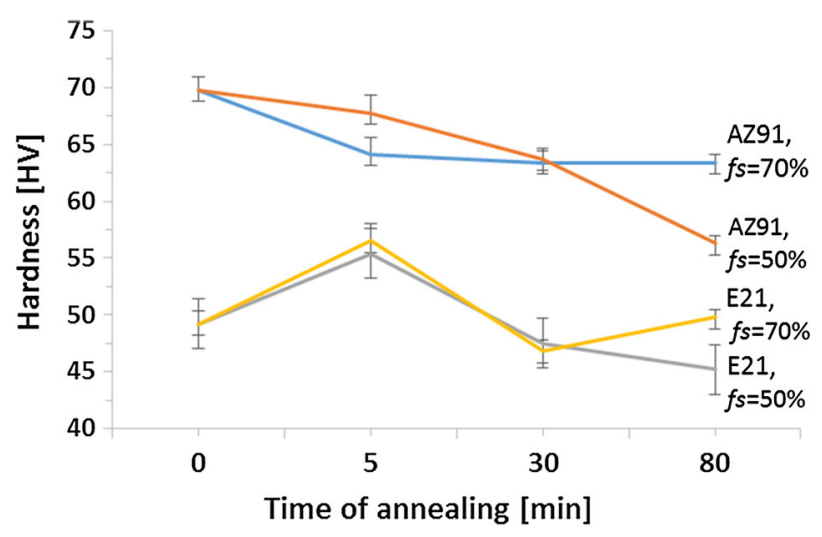

Fig. 8 Hardness changes vs. time of annealing of AZ91 and E21 at solid fraction 50 and $70 \%$

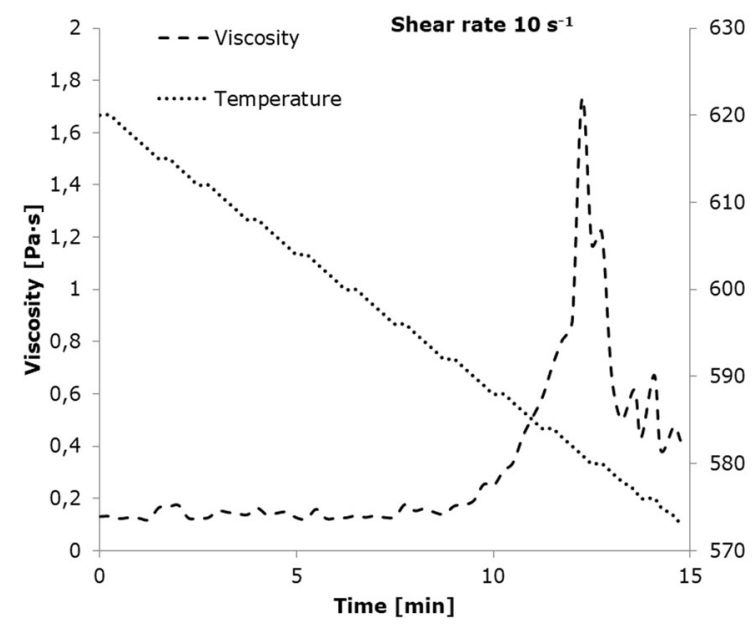

Fig. 9 Changes of dynamic viscosity of alloy AZ91 vs. temperature obtained during cooling from $620{ }^{\circ} \mathrm{C}$ (liquid phase) to $573{ }^{\circ} \mathrm{C}$ $\left(f_{s}=50 \%\right)$

observed the differences of apparent viscosity values in dependence on time of shearing (implemented force) which was caused by the microstructure changes (Ref 48). For measurements performed at higher shear rates (which will be presented hereinafter), for the liquid-phase share of $30 \%$, such high values (50 $\mathrm{Pa} \mathrm{s}$ ) of the dynamic viscosity coefficient were not observed.

The values of the dynamic viscosity (for changeable shear rate values $10-150 \mathrm{~s}^{-1}$ ) of alloy AZ91 at 50 and $70 \%$ of solid phase are presented in Fig. 11.

The dynamic viscosity coefficients for $50 \%$ solid fraction vary from about 0.85 to about $0.3 \mathrm{~Pa} \mathrm{~s}$ within the entire shear rate range. A decline of the viscosity of alloy AZ91 as shear rate increases indicates that the internal structure of the alloy was "destroyed" by the accelerating spindle (Ref 48). Alloy AZ91 shows a shear-thinning liquid behavior for both solidphase fractions, which is shown in Fig. 12; however, in the case of the $70 \%$ solid fraction, the dynamic viscosity coefficient was much bigger (about $60 \mathrm{~Pa} \mathrm{~s}$ ).

At the same time, during the tests conducted, it was found that when the alloy was subjected to a low shear rate, and therefore to a low force, its structure reconstructed, which was reflected by a slight increase in the dynamic viscosity

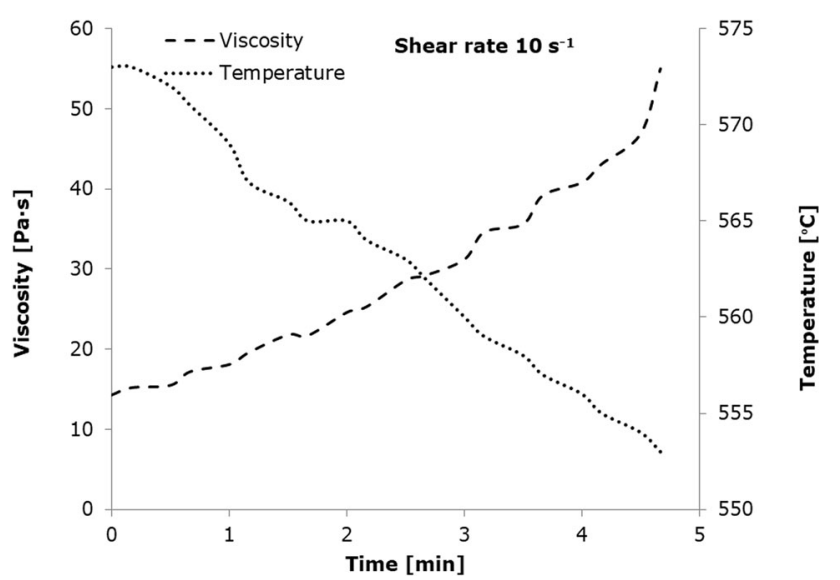

Fig. 10 Changes of dynamic viscosity of alloy AZ91 vs. temperature during cooling from $573{ }^{\circ} \mathrm{C}\left(f_{s}=50 \%\right)$ to $552{ }^{\circ} \mathrm{C}\left(f_{s}=70 \%\right)$

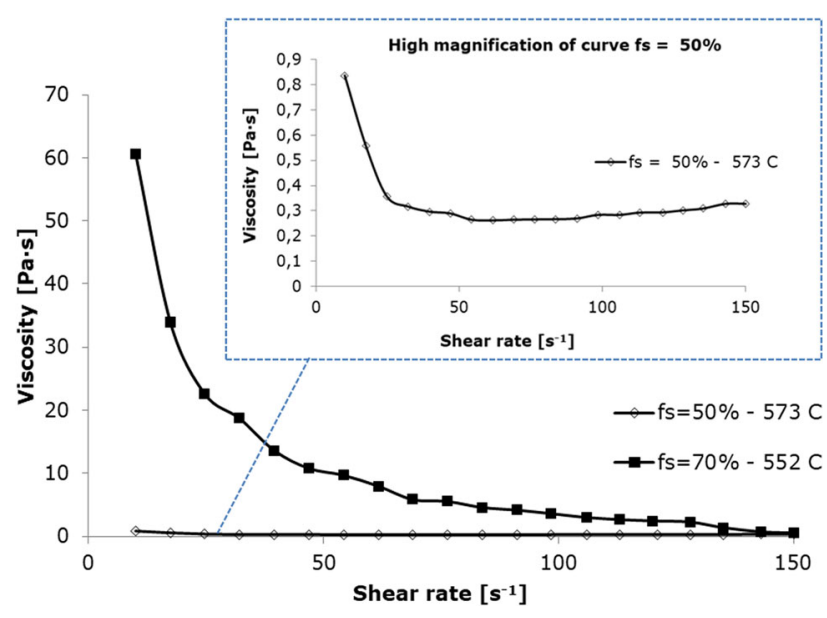

Fig. 11 Changes of dynamic viscosity of alloy AZ91 vs. shear rate, for two solid-phase shares in the alloy

coefficient. Chen and Chen also noticed that shear time and shear rate affected the microstructure and thus the rheological behavior of AZ91 (Ref 49).

Figure 12 presents changes of the dynamic viscosity coefficient of alloy AZ91 for the shear rate of $100 \mathrm{~s}^{-1}$.

As one can see, the viscosity during the 10-min measurement declined from the initial value of 10 to about $4 \mathrm{~Pa} \mathrm{~s}$. At the same time, much lower values of the coefficient for higher shear rates (for $f_{s}=70 \%$ and $\dot{\gamma}=10 \mathrm{~s}^{-1}, \eta=50 \mathrm{~Pa} \mathrm{~s}$ ) could be visible. This phenomenon is similar to the behavior of shearthinning bodies, for which the dynamic viscosity coefficient values decline as the force impacting the system grows. The continuous change of the coefficient could be caused by continuous destruction of the internal structure of the tested alloy by the rapidly turning measurement spindle (Ref 48). Moreover, at such a high solid-phase share (70\%), $10 \mathrm{~min}$ might not be enough for the AZ91 alloy viscosity to stabilize. However, the total measurement time was optimized to enable the experiment to be conducted on very reactive magnesium alloys, which immediately gets oxidized in contact with traces of oxygen.

The analogous measurements were taken for alloy E21. The results are presented in Fig. 13, in which changes of E21 alloy 


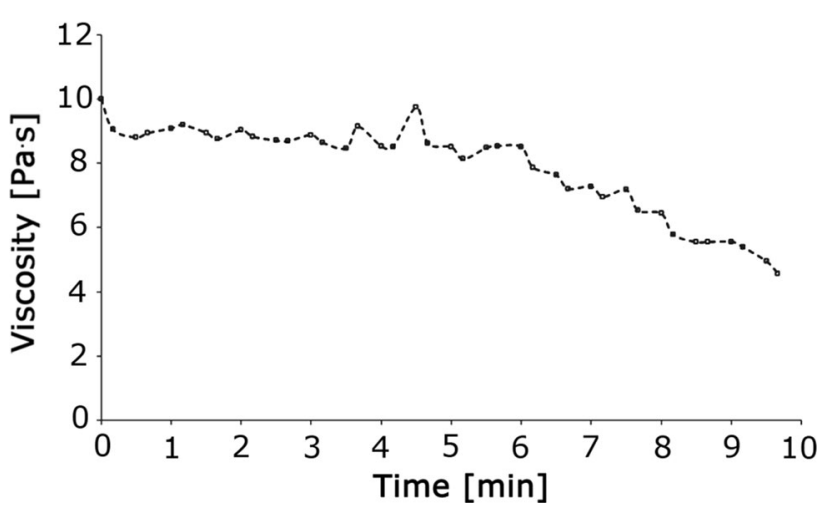

Fig. 12 Changes of dynamic viscosity coefficient of alloy AZ91, at $70 \%$ solid-phase share, and at shear rate $100 \mathrm{~s}^{-1}$

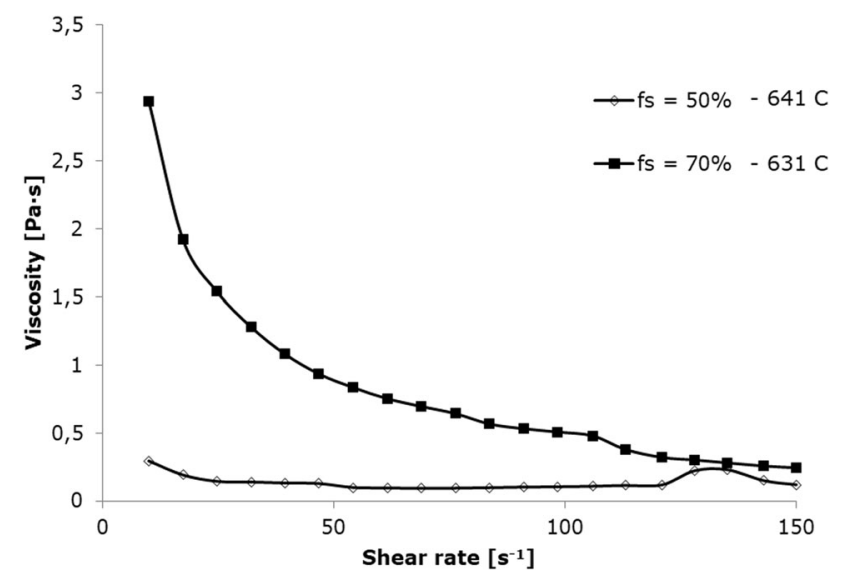

Fig. 13 Change in the dynamic viscosity coefficient of alloy E21 vs. shear rate, for two different solid-phase shares $\left(f_{s}=50\right.$ and $\left.70 \%\right)$

viscosity for various solid-phase shares and shear rates from 10 to $150 \mathrm{~s}^{-1}$ can be seen.

For both shares of the solid-phase fraction in the alloy tested, decline in the dynamic viscosity as the shear rate increased could be observed. It was likely to result from the "destruction" of the alloy internal structure by the faster and faster moving spindle. The alloy E21, similarly to AZ91, showed a shear-thinning behavior for both fractions of the solid phase. At the same time, during the tests, it was found that when the alloy was subjected to a low shear rate, and therefore to a low force, its structure reconstructed, which was reflected by a slight increase in the dynamic viscosity coefficient.

When analyzing the obtained results, one should bear in mind that the alloy examined during about 90 min of measurements was constantly subjected to variable forces. Therefore, the initial and "final" stages of the measurements conducted at the same shear rates are burdened by the "history" and the effect of a very fast rotating spindle on the internal structure. Such a "destruction" of the structure may result in obtaining slightly lower values of dynamic viscosity coefficient after a period of subjecting the alloy to high force (e.g., $150 \mathrm{~s}^{-1}$ ).

The examinations of alloy E21 were performed for the shear rate of $100 \mathrm{~s}^{-1}$ at $70 \%$ solid-phase content in the alloy (temp. $\left.631^{\circ} \mathrm{C}\right)$.

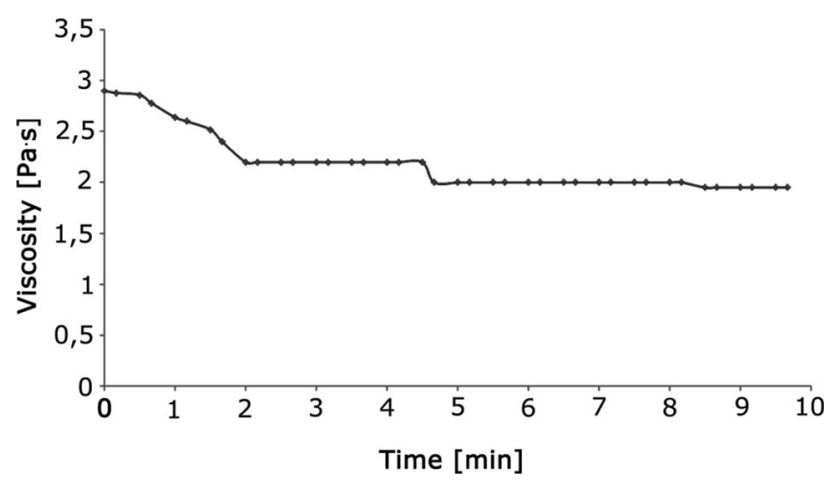

Fig. 14 Change in the dynamic viscosity coefficient of alloy E21, at $70 \%$ solid-phase share (temp. $631^{\circ} \mathrm{C}$ ), and at shear rate $100 \mathrm{~s}^{-1}$

Figure 14 presents changes in the dynamic viscosity coefficient of alloy E21, at the shear rate of $100 \mathrm{~s}^{-1}$.

The viscosity during the 10-min measurement declined from the initial value of 3 to about $2 \mathrm{~Pa} \mathrm{~s}$ after about $5 \mathrm{~min}$, in time necessary to stabilize the conditions in the entire sample volume. Interestingly, the time of $10 \mathrm{~min}$ was not enough to stabilize the conditions in the entire volume of the AZ91 alloy.

Rheological tests of magnesium alloys were difficult due to the high reactivity of the materials tested. They required considerable experience during the measurements and analysis of the obtained results. As part of the project, two magnesium alloys AZ91 and E21 were tested in conditions of variable rheological parameters. (The applied shear rates were between 10 and $150 \mathrm{~s}^{-1}$.) The experiments were performed at the liquidus temperature and at the temperatures of 50 and $70 \%$ solid-phase fraction in the alloy, calculated for each alloy with the DSC analysis. As a result of the conducted measurements, viscosity curves-describing the relationship between the dynamic viscosity coefficient and the shear rate, and changes of dynamic viscosity versus decreasing temperature-were obtained. The analysis of results showed that the highest dynamic viscosity coefficients were achieved for alloy AZ91, while the dynamic viscosity coefficient of alloy E21 reached only 2-3 $\mathrm{Pa} \mathrm{s}$, due probably to the contents of rare earth metals (yttrium, neodymium, gadolinium), which may be responsible for low values of dynamic viscosity coefficient. However, to verify the aforesaid statement, rheological tests of alloys with various contents of the above-mentioned rare earth metals should be performed.

In addition, all of the alloys tested showed a tendency to lower the value of the dynamic viscosity coefficient as the shear rate grew, which may indicate a tendency to shear-thinning, or a decline of the dynamic viscosity coefficient value resulting from the forces applied. This is one of key examples of the nonNewtonian behavior, characteristic for metals in the semi-solid state. At the same time, it was found that at slow impact with a low force (shear rate of $10 \mathrm{~s}^{-1}$ ) on the alloy tested, the coefficient slightly rose during shearing, which may indicate a slow reconstruction of the structure "destroyed" as a result of high forces at high values of shear rate, of $150 \mathrm{~s}^{-1}$ ).

\subsection{Softening Studies}

The easy softening test in the semi-solid temperature range was conducted in order to determine the initial temperature, in which the AZ91 and E21 alloys started to collapse. The constant load of $20 \mathrm{~N}$ was exerted during the experiment on 

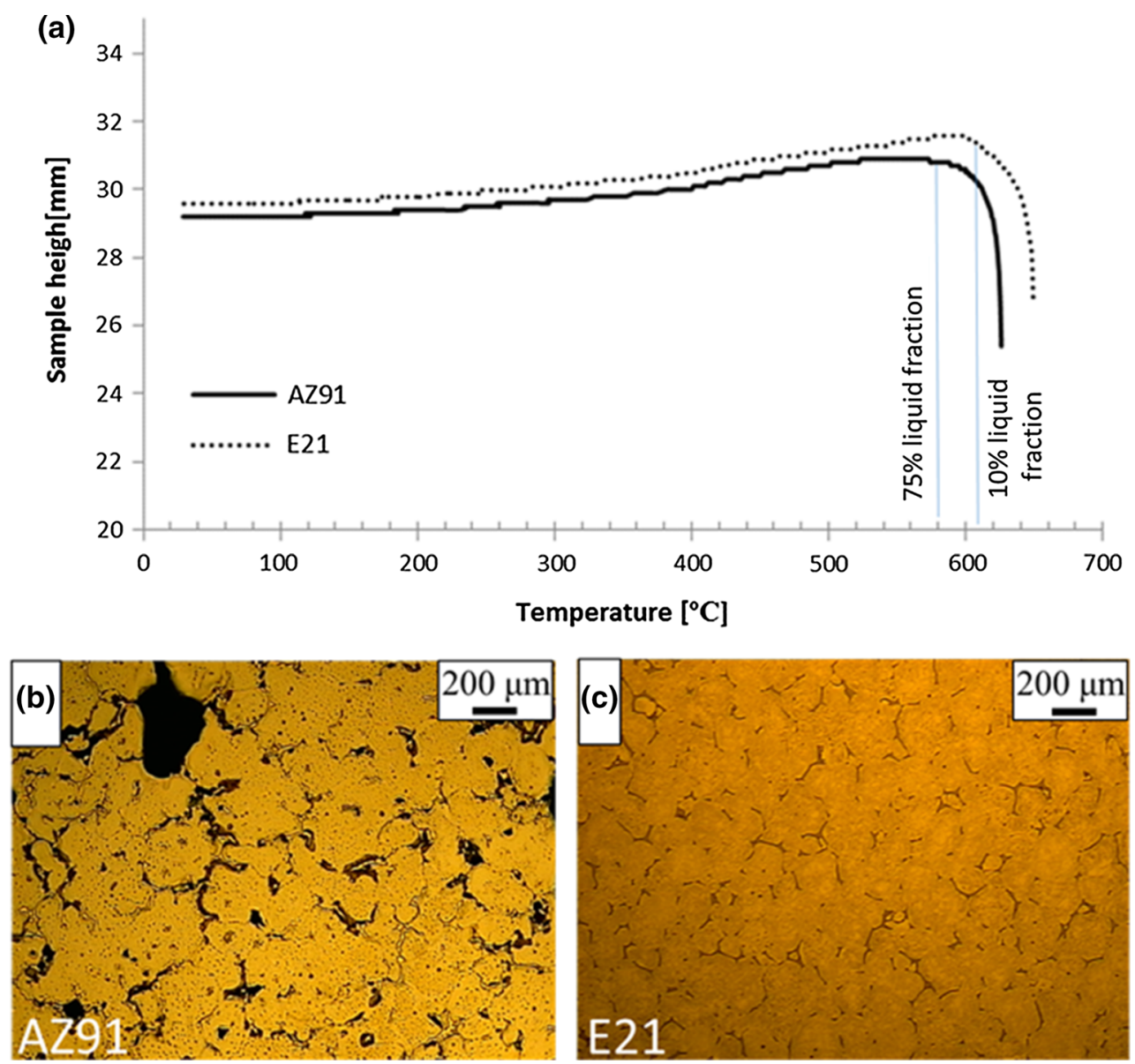

Fig. 15 (a) Graph presenting changes in sample height as a function of temperature obtained during continuous heating to semi-solid state of two kinds of magnesium alloys: AZ91 and E21. Microstructures after freezing of sample from temperature where alloys start to collapse (b) AZ91, (c) E21

two magnesium alloys heated up to the slurry region, and the displacement of stamp was measured.

Figure 15(a) presents dependency changes of height in a function of temperature. The analysis of graphs allowed establishing the similar behavior of both materials. The sample heights initially increased with temperature due to thermal expansion achieving their maximum at 570 and $595{ }^{\circ} \mathrm{C}$ for AZ91 and E21, respectively. Next, at 580 and $605{ }^{\circ} \mathrm{C}$, which corresponded to 75 and $10 \%$ of liquid fraction for AZ91 and E21 alloys, respectively, the movement of stamp was visibly suggesting collapsing/softening of the sample under load. AZ91 started to soften at a relatively high volume of liquid fraction, which could be connected with the internal microstructure of the sample. Figure 15(b) shows large irregular grains with size of 200-600 $\mu \mathrm{m}$, which interpenetrate forming a strong skeleton. It could be the reason that a low content of solid was required to break down the skeleton under 20 N. A completely different situation was in the case of the E21 alloy, which started softening at $10 \%$ liquid fraction, probably due to the presence of globular grains of $180 \mu \mathrm{m}$ size (Fig. 15c), which would rather not form the skeleton between globules due to the homogeneous distribution of eutectic separating them (in the semi-solid range). That was probably the reason that lower liquid content was needed the collapse to occur. Summarizing, the results showed that softening temperature strongly depended on the thermal history of alloy sand the chemical composition which in consequence largely affected the microstructure morphology in the semi-solid state. Shimahara et al. (Ref 53) reported that flow stress studied during upsetting of the X210CrW12 steel in the semi-solid state strongly depended on the initial state of microstructure. It has been consistent with our observation that two various compositions of materials and their different initial states led to significant differences in the behavior in their solidus-liquidus temperature ranges.

\section{Conclusion}

Two types of Mg alloys in a series of AZ91 and E21 were studied to characterize their microstructure and rheological behavior in the semi-solid range.

1. The globular microstructure after reaching the semi-solid temperature range was obtained in AZ91 alloy extruded rod by strain-induced melting activated process, while heterogeneous nucleation of $\operatorname{Mg}(\alpha)$ in as-cast E21 alloy was observed because of the presence of RE elements.

2. The coarsening rate of solid primary grains during isothermal holding in the semi-solid range, calculated using LSW rules, was significantly higher in the AZ91 
than in E21 alloy, due to the lack of stable precipitations limiting the grain growth. Ostwald ripening and coalescence resulted in grain density decrease with increasing time of annealing and temperature of soaking.

3. The highest values of dynamic viscosity coefficient were obtained for alloy AZ91, while those of alloy E21 achieved the maximum of 2-3 $\mathrm{Pa}$ s.

4. All examined alloys showed a tendency to lower the value of the dynamic viscosity coefficient as the shear rate grew, which suggested a non-Newtonian flow behavior and might indicate a tendency to shear-thinning of the systems tested.

\section{Acknowledgment}

Research project Leader No. 007/151/L-5/13/NCBR/2014, "Developing an innovative semi-solid forming process of a new generation of magnesium alloys and magnesium nano-composites," was financed by the National Centre for Research and Development. Research was also financed through statutory funds of AGH University of Science and Technology in Krakow, No. 11.11.110.502.

\section{Open Access}

This article is distributed under the terms of the Creative Commons Attribution 4.0 International License (http://creativecommons.org/ licenses/by/4.0/), which permits unrestricted use, distribution, and reproduction in any medium, provided you give appropriate credit to the original author(s) and the source, provide a link to the Creative Commons license, and indicate if changes were made.

\section{References}

1. S. Brown, Magnesium: A Structural Super-Metal, Thoughts and Reflections on the Use of Magnesium, G. Neighbour and I. Oraifige, Ed., Belmont Press, Northampton, 2017, p 3-5

2. M. Flemings, Solidification Processing, Metall. Trans., 1974, 5, p 2121-2134

3. G. Hirt, L. Khizhnyakova, R. Baadjou, F. Knauf, and R. Kopp, Semisolid Forming of Aluminium and Steel-Introduction and Overview, Thixoforming. Semi-solid Metal Processing, G. Hirt and R. Kopp, Ed., WILEY-VCH Verlag GmbH\&Co. KGaA, Weinheim, 2009, p 1-8

4. Z. Fan, Semi-solid Metal Processing, Int. Mater. Rev., 2002, 47(2), p 49-85

5. Y. Qi, T. Cagin, Y. Kimura, and W.A. Goddard III, Viscosities of Liquid Metal Alloys from Nonequilibrium Molecular Dynamics, $J$. Comput. Aided Mater. Des., 2001, 8, p 233-243

6. P. Zhao, Q. Wang, L. Liu, Z. Wei, and Ch. Zhai, Fluidity of Mg-Al-Ca Alloys in the High-Pressure Die Casting Process, Int. J. Mater. Res., 2007, 98(1), p 33-38

7. M. Huppmann and W. Reimers, Microstructure and Mechanical Properties of Differently Extruded AZ31 Magnesium Alloy, Int. J. Mater. Res., 2010, 101(10), p 1264-1271

8. K.N. Braszczyńska-Malik and L. Froyen, Microstructure of AZ91 Alloy Deformed by Equal Channel Angular Pressing, Int. J. Mater. Res., 2005, 96(8), p 913-917

9. J.Y. Chen and Z. Fan, Modelling of the Rheological Behavior of Semisolid Slurries, Part I: The Theory, Mater. Sci. Technol., 2002, 18, p 237-242

10. P. Terzieff, The Viscosity of Liquid Alloys, J. Alloys Compd., 2008, 453(1-2), p 233-240

11. R.P. Chhabra, A Simple Method for Estimating the Viscosity of Molten Metallic Alloys, J. Alloys Compd., 1995, 221(1-2), p L1-L3
12. H.V. Atkinson, Modelling the Semisolid Processing of Metallic Alloys, Prog. Mater Sci., 2005, 50, p 341-412

13. P. Kapranos and D.H. Kirkwood, Thixoforming M2 Tool Steel: A Study of Different Feedstock Routes, Metall. Ital., 2010, 9, p 17-21

14. P. Kapranos, D.H. Kirkwood, and C.M. Sellars, Semi-solid Processing of Aluminium and High Melting Point Alloys, Proc. Inst. Mech. Eng. B. J. Eng. manuf., 1993, 207(1), p 1-8

15. K.P. Sołek, Ł. Rogal, and P. Kapranos, Evolution of Globular Microstructure and Rheological Properties of Stellite 21 Alloy after Heating to Semisolid State, J. Mater. Eng. Perform., 2017, 26, p 115123

16. Ł. Rogal, J. Dutkiewicz, H.V. Atkinson, L. Lityńska-Dobrzyńska, T. Czeppe, and M. Modigell, Characterization of Semi-solid Processing of Aluminium Alloy 7075 with Sc and Zr Additions, Mater. Sci. Eng. A, 2013, 580, p 362-373

17. D. Brabazon, D.J. Browne, and A.J. Carr, Experimental Investigation of the Transient and Steady State Rheological Behaviour of Al-Si Alloys in the Mushy State, Mater. Sci. Eng. A, 2003, 356(1-2), p 69-80

18. M.S. Salleh, M.Z. Omar, J. Syarif, and M.N. Mohammed, An Overview of Semisolid Processing of Aluminium Alloys, ISRN Mater. Sci., 2013, 2013, p 1-9

19. P. Das, S.K. Samanta, and P. Dutta, Rheological Behavior of Al-7Si$0.3 \mathrm{Mg}$ Alloy at Mushy State, Metall. Mater. Trans. B, 2015, 46(3), p 1302-1313

20. O. Lashkari, F. Ajersch, A. Charette, and X. Chen, Microstructure and Rheological Behavior of Hypereutectic Semi-solid Al-Si Alloy Under Low Shear Rates Compression Test, Mater. Sci. Eng. A, 2008, 492(12), p 377-382

21. W.Y. Kim, C.G. Kang, and S.M. Lee, Effect of Viscosity on Microstructure Characteristic in Rheological Behaviour of Wrought Aluminium Alloys by Compression and Stirring Proces, Mater. Sci. Technol., 2010, 26(1), p 20-30

22. A. Bührig-Polaczek, C. Afrath, M. Modigell, and L. Pape, Comparison of Rheological Measurement Techniques for Semi-solid Aluminium Alloys, Solid State Phenom., 2006, 116-117, p 610-613

23. M. Kramer, R. Jenning, A. Lohmüller, M. Hilbinger, P. Randelzhofer, and R.F. Singer, Characterization of Magnesium Alloys for Semi Solid Processing, 8th International Conference on Magnesium Alloys and their Applications, Oct 26-29, 2009 (Weimar), p 376-383

24. M. Modigell, L. Pape, and H.R. Maier, Rheology of Semi-solid Steel Alloys at Temperatures up to 1500 C, Solid State Phenom., 2006, 116, p 606-609

25. Y. Hong, R. Yuansheng, and Ch Guoxiang, Rheological Behavior of Semi-solid AZ91D Magnesium Alloy at Steady State, J. Wuhan Univ. Technol. Mater. Sci. Ed., 2015, 30(1), p 162-165

26. M. Korolczuk-Hejnak and P. Migas, Analysis of Selected Liquid Steel Viscosity, Arch. Metall. Mater., 2012, 57(4), p 963-969

27. K. Miłkowska-Piszczek and M. Korolczuk-Hejnak, An Analysis of the Influence of Viscosity on the Numerical Simulation of Temperature Distribution, as Demonstrated by the CC Proces, Arch. Metall. Mater., 2013, 58(4), p 1267-1274

28. M. Korolczuk-Hejnak, Determination of Flow Curves on Selected Steel Grades in Their Liquid State, Arch. Metall. Mater, 2014, 59(4), p $1553-1558$

29. W. Ślęzak, M. Korolczuk-Hejnak, and P. Migas, High Temperature Rheometric Measurements of Mould Powders, Arch. Metall. Mater., 2015, 60(1), p 289-294

30. M. Korolczuk-Hejnak, Determination of the Dynamic Viscosity Coefficient Value of Steel Based on the Rheological Measurements, Wydawnictwa AGH, Kraków, 2014 ((in Polish))

31. M. Ślęzak, Mathematical Models for Calculating the Value of Dynamic Viscosity of a Liquid, Arch. Metall. Mater, 2015, 60(2A), p 581589

32. M. Korolczuk-Hejnak, Empiric Formulas for Dynamic Viscosity of Liquid Steel Based on Rheometric Measurements, High Temp., 2014, 52(5), p 667-674

33. Z. Kembłowski, Reometria Płynów Nienewtonowskich, Wydawnictwo Naukowo-Techniczne, Warszawa, 1973 ((in Polish))

34. S. Bakhtiyarov and R. Overfelt, Measurement of Liquid Metal Viscosity by Rotational Technique, Acta Mater, 1999, 47(17), p 4311-4319

35. G.T. Mezger, The Rheology Handbook: For Users of Rotational and Oscillatory Rheometers, 2nd ed., Vincentz Network, Hannover, 2006, p 171-198 
36. X.J. Wang, S.M. Zhu, M.A. Easton, M.A. Gibson, and G. Savage, Heat Treatment of Vacuum High Pressure Die Cast Magnesium Alloy AZ91, Int. J. Cast Met. Res., 2014, 27(3), p 161-166

37. D. Qiua and M.-X. Zhang, Effect of Active Heterogeneous Nucleation Particles on the Grain Refining Efficiency in an Mg-10 wt\% Y Cast Alloy, J. Alloys Compd., 2009, 488(1), p 260-264

38. M.M. Avedesian and H. Baker, Ed., ASM Specialty Hand Book, Magnesium and Magnesium Alloys, ASM International, The Mater. Information Society, Ohio, 1999, p 54

39. L.L. Rokhlin, Magnesium Alloys Containing Rare Earth Metals: Structure and Properties, Advances in Metallic Alloys, J.N. Fridlyander, G.G. Eskin, Eds., Taylor \& Francis, London and New York, 2003

40. A. Kiełbus, Microstructure and Properties of Elektron 21 Magnesium Alloy, Magnesium Alloys-Design, F. Czerwinski, Ed., Processing and Properties, InTech, Rijeka, 2011,

41. T.B. Massalski, H. Okamoto, P.R. Subramanian, L. Kacprzak, Eds., Binary Alloy Phase Diagrams, 2nd ed., ASM International, Ohio, 1990

42. Ł. Rogal, Critical Assessment: Opportunities in Developing Semi-solid Processing: Aluminium, Magnesium, and High-Temperature Alloys, Mater. Sci. Technol., 2017, 33(7), p 759-764

43. E.D. Manson-Whitton, I.C. Stone, J.R. Jones, P.S. Grant, and B. Cantor, Isothermal Grain Coarsening of Spray Formed Alloys in the Semi-solid State, Acta Mater, 2002, 50, p 2517-2535

44. F. Czerwinski, Semi-solid Processing of Magnesium Alloys: Microstructure-Property Relationship, Solid State Phenom., 2015, 217-218, p 3-7
45. I.M. Lifshitz and V.V. Slyozov, The Kinetics of Precipitation from Supersaturated Solid Solutions, J. Phys. Chem. Solids, 1961, 19(1-2), p $35-50$

46. C. Wagner, Theory of Precipitate Change by Redissolution, $Z$. Elektrochem. Angew. Phys. Chem., 1961, 65, p 581-591

47. W.D. Callister, Fundamentals of Materials Science and Engineering, 2nd ed., Wiley, Weinheim, 2000

48. D.Y. Chang and S.S. Kwang, Semi-solid Processing of Magnesium Alloys, Mater. Trans., JIM, 2003, 44, p 558-561

49. H.I. Chen and J.C. Chen, Thixotropic Behavior of Semi-solid Magnesium Alloy, Solid State Phenom., 2006, 116-117, p 648-651. https://doi.org/10.4028/www.scientific.net/SSP.116-117.648

50. H.I. Chen, J.C. Chen, and J.J. Liao, The Influence of Shearing Conditions on the Rheology of Semi-solid Magnesium Alloy, Mater. Sci. Eng. A, 2008, 487, p 114-119. https://doi.org/10.1016/j.msea. 2007.09.072

51. Y. Hu, B. He, and H. Yan, Rheological Behavior of Semi-solid Mg2Si/ AM60 Magnesium Matrix Composites at Steady State, Trans. Nonferr. Metal. Soc. China, 2010, 20, p 883-887. https://doi.org/10.1016/ S1003-6326(10)60600-0

52. L. Li and M. Zheng, Theoretical Research on Rheological Behavior of Semisolid Slurry of Magnesium Alloy AZ91D, Comput. Mater. Sci., 2015, 102, p 202-207. https://doi.org/10.1016/j.commatsci.2015.02. 033

53. H. Shimahara, R. Baadjou, R. Kopp, and G. Hirt, Investigation of Flow Behaviour and Microstructure on X210CrW12 Steel in Semi-solid State, Solid State Phenom., 2006, 116-117, p 189-192 